\section{Damage limitation}

\section{Stuart Sutherland}

Classic Cases in Neuropsychology. Edited by Chris Code, Claus-W. Wallesch, Yves Joanette and Andre Roch Lecours. Lawrence Erlbaum: 1996. Pp. 385. £34.95.

PsychOLOGY, like shirts and skirts, is subject to the vagaries of fashion. Currently in vogue, particularly in the United Kingdom, is the examination of the effects of brain damage, whether caused by surgery, tumours or strokes, a discipline loosely known as neuropsychology (although that term can be applied to other approaches to brain function). The founder of the method was effectively Paul Broca, who in 1861 concluded that an area of the left frontal lobe produced motor aphasia the inability to talk, with other motor functions and the capacity to understand speech left reasonably intact. Progress has been aided recently by the development of sophisticated brain scans, such as electromagnetic resonance, which can locate the site of a lesion while the patient is still alive.

The contributors to Classic Cases in Neuropsychology each describe the history of an important case or cases ranging from Broca to modern times, connecting them with recent research and theorizing. Neuropsychologists have shown that even higher cognitive processes are modular: that is, particular parts of the brain are involved in each. For example, some patients are unable to read, but their capacity to recognize objects other than words and their ability to write are only marginally impaired. Again, some exhibit a curious error of reading - when asked

\section{New in paperback}

Reflections of Eden: My Life with the Orangutans of Borneo by Biruté M. F. Galdikas. Indigo, $£ 7.99$. “Unlike the books by her fellow trimates [Jane Goodall and Dian Fossey], Reflections of Eden is highly egocentric, sometimes frustratingly so", W. C. McGrew, Nature 374, 832 (1995).

Charles Darwin: Voyaging - Volume 1 of a Biography by Janet Browne. "Her qualifications as a trained biologist, historian of science and skilled editor of the correspondence put her in an ideal position.... A wonderful read", P. R. Sloan, Nature 374, 829 (1995).

Feral Children and Clever Animals: Reflection on Human Nature by Douglas Keith Candland. Oxford University Press, £12.99. \$16.95. “An eye-opening history of psychology”, Andrew Whiten, Nature 366, 375 (1993). to read words aloud they provide the wrong word, but one of the same semantic category as that presented: they may say 'chair' when shown 'table'. These mistakes therefore arise not at a perceptual level but after the word's meaning has been extracted. Again, there is the inability to recognize faces (prosopagnosia) while still being able to recognize certain aspects of them such as the direction of gaze.

Although neuropsychology has revealed where certain tasks are carried out in the brain, it has not yet thrown much light on how they are conducted, which is much the more interesting question. One notable exception is cases showing that the ability to store material in long-term memory can be abolished through brain damage while leaving short-term memory intact (for instance, repeating a string of telephone numbers), combined with a case in which short-term memory was eliminated but the person's long-term memory was preserved. This discredited the existing theory that material was passed from short-term to long-term memory, though, as so often, even this conclusion is not completely firm: it might be that the lesion made it impossible to retrieve material from short-term memory while the capacity to store such material briefly and pass it on to long-term memory was intact. Indeed, despite the fascination of these cases, there are few whose explanation has not remained controversial. Some believe that prosopagnosia can be an isolated effect, others that other forms of visual recognition are affected. It is difficult if not impossible to find lesions limited to an area that subserves a single function. Moreover, as one contributor warns, "Patients always present with a large variety of symptoms, of which only a minor portion are usually described in case studies".

Most of the contributors limit themselves to brain lesions in humans, but such work should be interpreted in the context of other approaches, including work on animals, which has the advantage that it is possible to make more precise lesions and also to stimulate or record directly from the brain. On the other hand, animals have the unfortunate disadvantage that they can neither speak nor write. There is, moreover, little mention of brain scans, which can be used to measure blood flow: if blood flow increases in a particular area while the subject is performing a certain task, then that area is probably implicated in the task.

Finally, because the book is organized around specific cases, some of the important findings of neuropsychology are ignored. For example, different lesions can destroy the ability to deal with different and specific categories: a lesion to part of the motor area selectively damages the capacity to recognize tools, suggesting that such recognition is at least partially based on a knowledge of how to use them.

Classic Cases in Neuropsychology is an interesting and formidably scholarly book, but it is not easy reading and will appeal mainly to specialists. Some chapters correct errors that have crept into the literature, particularly from early German work that has never been translated. Given their aims, the editors have done a good job, covering aphasia, alexia, agnosia and so on, although a few of their contributors appear to be suffering from agraphia themselves.

Stuart Sutherland is in the Laboratory of Experimental Psychology, University of Sussex, Brighton BN1 9QG, UK.

\section{Niche fillers}

\section{G. E. Fogg}

Algae: An Introduction to Phycology. By $C$ van den Hoek, D. C. Mann and H. J. Jahns. Cambridge University Press: 1996. Pp. 623. £70, \$110 (hbk); £24.95, \$39.95 (pbk).

THE rag-bag of organisms grouped as algae ranges in size over eight orders of magnitude and includes both prokaryotes and eukaryotes with little in common except oxygenic photosynthesis. Nevertheless, phycology has persisted as a distinct science and calls for textbooks surveying the whole of its catholic field.

Half a century ago, F. E. Fritsch managed to put nearly everything known about algae into a scholarly treatise, using the theme of parallel evolution in the different classes to give the work coherence. Since then, electron microscopy and molecular biology have provided insights leading not just to the overhaul of classification but also to the realization that the algae display a major evolutionary radiation at the cellular level. The phycologist's instinct that these organisms should be studied as a single group has been spectacularly vindicated.

Algae is an updated version of a highly successful German text. It presents traditional life histories and morphology, together with salient features of ecology and physiology, but concentrates on modern concepts of phylogenesis. It is excellently illustrated, mostly using clear line drawings of fine structure rather then electron micrographs.

Phycologists will keep Fritsch's volumes on their shelves, but this new book will displace others alongside and take over the wear and tear of everyday use by both student and research worker.

C. E. Fogg is at the Marine Science Laboratories, Menai Bridge, Gwynedd LL59 5EY, UK. 